\title{
AVALIAÇÃO DE DIFERENTES COMPOSIÇÕES DE SUBSTRATOS NA PRODUÇÃO DE MUDAS DE MORANGO FORA DO SOLO
}

Luciene Laurett $^{1}$, João Nacir Colombo ${ }^{2}$, Ivan Caldeira Almeida Alvarenga ${ }^{3}$

${ }^{1}$ Acadêmica de Agronomia, Instituto Federal do Espírito Santo - Campus Santa

Teresa; Rodovia ES-080, Km 93 s/n, Santa Teresa - ES, 29660-000

${ }^{2}$ Professor-Instituto Federal do Espírito Santo - Campus Santa Teresa; Rodovia ES080, Km 93 s/n, Santa Teresa - ES, 29660-000

${ }^{3}$ Engenheiro Agrônomo, Secretaria Municipal de Agricultura de Fundão, Fundão-ES, Rua Sizenando Braga, 43, CEP:29185-000. Email: pytchoagro@yahoo.com.br

\section{Recebido em: 15/08/2021 - Aprovado em: 15/09/2021 - Publicado em: 30/09/2021 DOI: 10.18677/EnciBio_2021C8}

\section{RESUMO}

A produção das mudas no sistema denominado fora do solo é uma alternativa econômica para os produtores de morango, no entanto, é necessário um substrato adequado para o pleno desenvolvimento das mudas. Com isso, o objetivo do trabalho foi avaliar a composição de diferentes substratos na produção de mudas de morangueiro Cv. Albion através do sistema fora do solo em Alto Rio Plantoja, localidade tradicionalmente produtora de morangos em Santa Maria de Jetibá, ES. Foram avaliados sete substratos: $100 \%$ terra vegetal; as proporções de $90 \%$ terra vegetal $+10 \%$ de esterco bovino curtido; $80 \%$ terra vegetal $+20 \%$ de esterco bovino curtido; $70 \%$ terra vegetal $+30 \%$ de esterco bovino curtido; $60 \%$ terra vegetal $+40 \%$ de esterco bovino curtido; $50 \%$ terra vegetal $+50 \%$ de esterco bovino curtido e $100 \%$ substrato comercial. O delineamento utilizado foi o de blocos inteiramente casualizados, com quatro repetições. Aos 30 dias de cultivo foram avaliadas: altura da planta, diâmetro do caule, número de folhas, massa de matéria fresca da parte aérea, massa de matéria fresca das raízes, volume da raiz, massa de matéria seca da parte aérea, massa de matéria seca das raízes e o índice de qualidade de Dickson. As médias foram comparadas pelo teste Tukey a $5 \%$ de probabilidade. Pelos resultados observados, o substrato comercial se destacou dos demais tratamentos nos parâmetros número de folhas, volume de raiz e matéria seca de raiz. Assim, recomenda-se a utilização de substrato comercial para a produção de mudas "fora do solo" em morangueiro.

PALAVRAS-CHAVE: Agricultura Familiar, Estolão, Propagação Vegetativa. 


\title{
EVALUATION OF DIFFERENT SUBSTRATE COMPOSITIONS IN THE PRODUCTION OF OFF-SOIL STRAWBERRY SEEDLINGS
}

\begin{abstract}
The production of seedlings in the system called off-soil seedlings is an economic alternative for strawberry producers, however, an adequate substrate is necessary for the full development of the seedlings. Thus, the objective of this work was to evaluate the composition of different substrates in the production of strawberry Cv. Albion through the off-soil system in Alto Rio Plantoja, traditionally producing strawberries in Santa Maria de Jetibá, ES. Seven substrates were evaluated: $100 \%$ topsoil; the proportions of $90 \%$ topsoil $+10 \%$ of tanned cattle manure; $80 \%$ topsoil + $20 \%$ tanned cattle manure; $70 \%$ topsoil $+30 \%$ tanned cattle manure; $60 \%$ topsoil + $40 \%$ of tanned cattle manure; $50 \%$ topsoil $+50 \%$ tanned cattle manure and $100 \%$ commercial substrate. The design used was a completely randomized blocks, with four replications. At 30 days of cultivation, the following parameters were evaluated: plant height, stem diameter, number of leaves, shoot fresh matter mass, roots fresh matter mass, root volume, shoot dry matter mass, mass of matter root drought and the Dickson quality index. Means were compared by Tukey test at $5 \%$ probability. From the results observed, the commercial substrate stood out from the other treatments in the number of leaves, root volume and root dry mass. Thus, it is recommended to use commercial substrate for the production of off-soil seedlings in strawberry.
\end{abstract}

KEYWORDS: Family Farming, Vegetative Propagation, Stolon.

\section{INTRODUÇÃO}

A cadeia produtiva do morangueiro é considerada uma das mais significativas no setor de horticultura (ANTUNES e REISSER JUNIOR 2019). Do ponto de vista socioeconômico, o morango é uma espécie importante, sendo caracterizada pela rentabilidade e emprego intensivo de mão de obra (NINK et al., 2016). A alta rentabilidade por área quando comparada a outras culturas, é uma das principais características que tem despertado o interesse dos agricultores familiares na cultura do morango (WURZ et al., 2019).

O Espírito Santo possui uma área plantada de aproximadamente 300 hectares de morangueiro. A maior parte da produção está concentrada nos municípios de Domingos Martins, Venda Nova do Imigrante, Santa Maria de Jetibá e Afonso Cláudio, considerados como a região do Pólo de Morango no Estado (INCAPER, 2021).

No último ano, foram comercializados pelas unidades Centrais de Abastecimento do Espírito Santo (CEASA-ES, 2020), $900 \mathrm{Kg}$ do fruto, sendo o município de Santa Maria de Jetibá o principal fornecedor, responsável por $61,11 \%$ do morango comercializado (CEASA-ES, 2020). O município de Santa Maria de Jetibá é o maior produtor de morango do estado do Espírito Santo, com destaque para o distrito de São João do Garrafão (PMSMJ, 2017).

Uma das limitações enfrentadas pelos produtores de morango em Santa Maria de Jetibá é a dificuldade na aquisição de mudas. A baixa quantidade e qualidade das mudas produzidas pelos viveiristas locais, não especializados na cultura, tornam os produtores dependentes de mercados externos de mudas, o que acarreta atrasos no estabelecimento da lavoura e reduz a produção precoce de frutos (ZEIST et al., 2019). 
A obtenção de mudas é uma das etapas mais importantes para o sucesso do cultivo do morangueiro, pois envolve decisões gerenciais relevantes, como a qualidade do material propagativo, o preço, a disponibilidade e a escolha da cultivar (ROKA;GUAN, 2018). A aquisição de mudas do morangueiro corresponde por cerca de $20 \%$ em média do custo de produção total (RANGEL JUNIOR, 2020).

A produção de mudas de morangueiro em sistema fora do solo é uma tecnologia recente no Brasil, apresentando-se como uma alternativa economicamente viável e que apresenta vantagens em relação à produção tradicional no solo (COCCO et al., 2016). Adicionalmente a esse processo, podemse ser utilizados substratos alternativos ao substrato comercial, com recursos da propriedade, diminuindo ainda mais os custos de produção de mudas. Cabe salientar que o substrato deve apresentar características físicas, químicas e sanitárias que permitam o pleno crescimento das raízes, proporcionando mudas sadias e desenvolvidas (WATERS;WATSON 2015).

Assim, o presente trabalho teve por objetivo avaliar diferentes composições de substratos para a produção de mudas de morango, através do método fora do solo, em plantio conduzido no município na comunidade de Alto Rio Plantoja, Santa Maria de Jetibá-ES, composta por propriedades voltadas para a prática da agricultura familiar, onde em aproximadamente $50 \%$ das propriedades cultiva-se morango (GRUGIKI et al., 2014).

\section{MATERIAL E MÉTODOS}

O experimento foi realizado durante o mês de novembro e dezembro do ano de 2019, em uma propriedade familiar denominada Sítio Laurett, localizada na comunidade de Alto Rio Plantoja, município de Santa Maria de Jetibá, Espírito Santo. O clima da região, segundo a classificação de Köppen, é do tipo Cwa, tropical de altitude, com temperaturas variando de $\left(25,3^{\circ}\right.$ a $27,8^{\circ}$ no verão $)$ e $\left(7,3^{\circ}\right.$ a $9,4^{\circ}$ no inverno), a precipitação média anual é de 1258,6 mm (INCAPER, 2021).

Em um plantio de morangueiro, cultivar Albion, com 180 dias após transplantio (DAT), instalado em sistema protegido com túneis baixos, sistema de irrigação localizada por gotejo e fertirrigação, foram escolhidas as plantas matrizes. Utilizou-se como planta matriz a planta que apresentava as melhores características vegetativo-produtivas e com bom estado fitossanitário. Foram selecionados estolhos sadios com um par de folhas bem desenvolvido e com raízes em torno de $1 \mathrm{~cm}$. Aos 15 dias do mês de novembro, o estolho foi fixado em copos plásticos com capacidade de $200 \mathrm{~mL}$.

O delineamento experimental utilizado foi em blocos ao acaso, com sete tratamentos e quatro repetições, sendo utilizadas três plantas por tratamento para cada repetição. Os tratamentos foram: $100 \%$ terra vegetal (T1); $90 \%$ terra vegetal + $10 \%$ de esterco bovino curtido (T2), $80 \%$ terra vegetal $+20 \%$ de esterco bovino curtido (T3); $70 \%$ terra vegetal $+30 \%$ de esterco bovino curtido (T4); $60 \%$ terra vegetal $+40 \%$ de esterco bovino curtido (T5); $50 \%$ terra vegetal $+50 \%$ de esterco bovino curtido (T6); $100 \%$ substrato comercial Bioplant ${ }^{\circledR}$ (T7).

Os substratos foram preparados através da homogeneização manual e colocados em copos plásticos com volume de $200 \mathrm{~mL}$. Os copos foram devidamente identificados de acordo com os tratamentos e repetições. Próximo à planta matriz foi inserido o copo plástico de forma que o estolão fosse conduzido até o mesmo e fixado sobre o substrato. A irrigação foi realizada uma vez ao dia adicionando-se um volume de água suficiente para saturar o substrato. 
Transcorridos 30 dias da fixação do estolho no substrato, foram realizadas as análises biométricas. As características biométricas avaliadas foram: altura da planta (A), diâmetro do caule (DC), número de folhas (NF), massa de matéria fresca da parte aérea (MFPA), massa de matéria fresca das raízes (MFR), volume da raiz (VR), massa de matéria seca da parte aérea (MSPA), massa de matéria seca das raízes (MSR) e o índice de qualidade de Dickson (IQD) (DICKSON et al., 1960).

A altura das plantas foi determinada com auxílio de uma régua a partir do nível do substrato até a extremidade das folhas mais altas, expressa em centímetros. O diâmetro do caule foi medido com o auxílio de um paquímetro e expresso em milímetros. Para a determinação da massa de matéria fresca das variáveis avaliadas, foi utilizada uma balança analítica com três casas decimais. Para determinação da massa de matéria seca, o material foi colocado para secar em estufa com circulação contínua de ar a $72{ }^{\circ} \mathrm{C}$ até o material atingir peso constante. $O$ volume da raiz foi calculado através do método da proveta, pela diferença entre $o$ volume inicial e o final, após colocação das raízes. Os dados foram submetidos à análise de variância, e quando significativo, realizado o teste Tukey, com intervalo de confiança de $95 \%$, através do programa Genes ${ }^{\circledR}$ (CRUZ, 2013).

\section{RESULTADOS E DISCUSSÃO}

Observa-se na Figura 1 o aspecto geral das mudas, onde notadamente $\mathrm{o}$ substrato comercial (T7) se destaca dos demais tratamentos. De acordo com as análises estatísticas, houve efeito significativo para as variáveis: volume de raiz, número de folhas e matéria fresca da raiz (Tabela 1). Para todas as demais variáveis, não foi observado interação significativa entre os tratamentos. As maiores médias referentes aos parâmetros relativos ao desempenho do sistema radicular foram obtidas no T7 (substrato Bioplant $^{\circledR}$ ). Isso pode ter ocorrido em função do maior espaço de aeração (EA) desse substrato.

FIGURA 1. Aspecto geral de mudas de morangueiros cv. Albion, com 30 dias de plantio, sob diferentes composições de substrato, Santa Maria de Jetibá, ES, 2019.

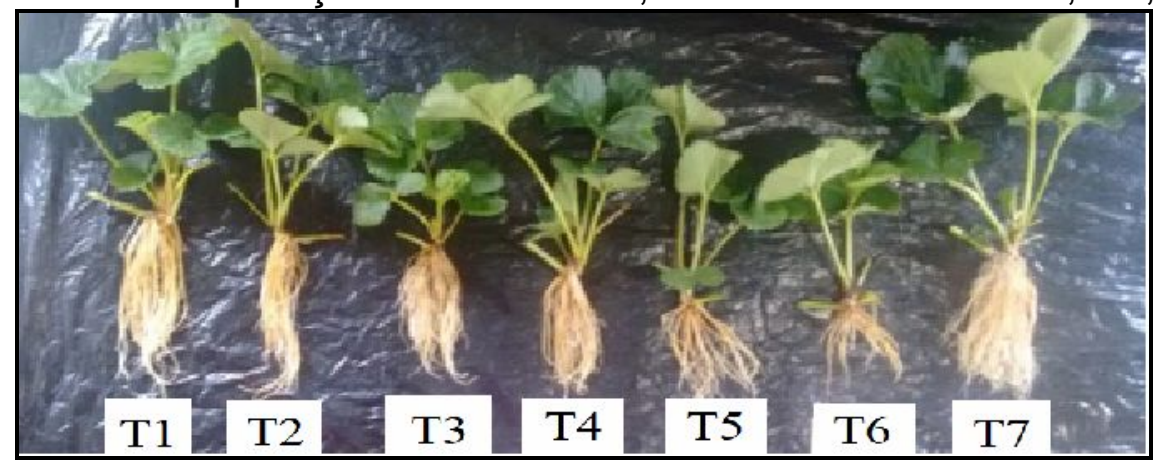

Fonte: Os autores (2019) 
TABELA 1-Variáveis biométricas de mudas de morangueiro cv.Albion, com 30 dias de plantio, sob diferentes composições de substrato, Santa Maria de Jetibá, ES, 2019.

\begin{tabular}{|c|c|c|c|c|c|c|c|c|c|c|c|c|}
\hline \multirow{2}{*}{\multicolumn{2}{|c|}{ Tratamentos }} & \multirow{2}{*}{ NF } & \multirow{2}{*}{$\frac{\text { ALT }}{\mathrm{cm}}$} & \multirow{2}{*}{$\frac{\mathrm{DCO}}{\mathrm{mm}}$} & \multirow{2}{*}{$\frac{\text { VR }}{\mathrm{cm}^{3}}$} & MFPA & MFR & MFT & MSPA & MSR & MST & \multirow{2}{*}{ IQD } \\
\hline & & & & & & \multicolumn{6}{|c|}{ g. planta $^{-1}$} & \\
\hline $\mathrm{T} 1$ & $100 \%$ TV & $4,40^{*}$ & $11,33^{\text {ns }}$ & $10,43^{\text {ns }}$ & $3,12^{*}$ & $10,41^{\text {ns }}$ & $3,83^{*}$ & $14,25^{\mathrm{ns}}$ & $1,60^{\text {ns }}$ & $0,71^{\text {ns }}$ & $2,31^{\mathrm{ns}}$ & $1,94^{\mathrm{ns}}$ \\
\hline T2 & $\begin{array}{c}90 \% \text { TV }+10 \% \\
\text { ES }\end{array}$ & $4,15 \mathrm{~b}$ & 10,62 & 9,19 & $3,33 \mathrm{~b}$ & 8,50 & $3,58 \mathrm{~b}$ & 12,08 & 1,04 & 0,70 & 1,74 & 1,31 \\
\hline T3 & $\begin{array}{c}80 \% \text { TV }+20 \% \\
\text { ES } \\
\end{array}$ & $4,78 \mathrm{~b}$ & 10,78 & 9,75 & $3,50 \mathrm{~b}$ & 9,33 & $3,83 b$ & 13,16 & 1,25 & 0,66 & 1,91 & 1,44 \\
\hline $\mathrm{T} 4$ & $\begin{array}{c}70 \% \text { TV }+30 \% \\
\text { ES }\end{array}$ & $7,08 \mathrm{a}$ & 10,54 & 10,47 & $3,92 \mathrm{~b}$ & 6,83 & $4,14 \mathrm{~b}$ & 10,97 & 1,61 & 0,66 & 2,27 & 1,74 \\
\hline T5 & $\begin{array}{c}60 \% \text { TV }+40 \% \\
\text { ES }\end{array}$ & $4,18 \mathrm{~b}$ & 10,83 & 9,65 & $3,04 \mathrm{~b}$ & 8,75 & $3,50 \mathrm{~b}$ & 12,24 & 1,00 & 0,53 & 1,52 & 0,90 \\
\hline $\mathrm{T} 6$ & $\begin{array}{c}50 \% \text { TV }+50 \% \\
\text { ES }\end{array}$ & $4,98 \mathrm{~b}$ & 11,10 & 9,30 & $1,46 \mathrm{c}$ & 8,50 & $2,66 \mathrm{~b}$ & 11,16 & 0,98 & 0,29 & 1,27 & 0,42 \\
\hline T7 & $\begin{array}{l}\text { Substrato } \\
\text { Comercial }\end{array}$ & $7,08 \mathrm{a}$ & 11,71 & 10,11 & $6,25 a$ & 11,91 & $6,83 a$ & 18,74 & 1,80 & 0,76 & 2,56 & 2,04 \\
\hline & CV\% & 17,17 & 13,55 & 10,78 & 25,31 & 26,71 & 22,95 & 20,74 & 26,14 & 24,18 & 25,07 & 28,10 \\
\hline
\end{tabular}

Medias seguidas pela mesma letra na coluna, não se diferenciam entre si pelo teste Tukey a $5 \%$ de probabilidade. TV-terra vegetal; ES-esterco bovino curtido; número de folhas (NF), altura da planta (ALT), diâmetro do caule (DCO), volume da raiz (VR), matéria fresca da parte aérea (MFPA), matéria fresca das raízes (MFR), matéria fresca total (MFT) matéria seca da parte aérea (MSPA), matéria seca das raízes (MSR) matéria seca total (MST) e o índice de qualidade de mudas de Dickson (IQD).

A análise isolada das variáveis biométricas indicou que a proporção 1:1 terra e esterco bovino (T6) apresentou menores médias entre os tratamentos. Resultado semelhante foi observado por Moura et al., (2014) avaliando diferentes substratos para a produção de mudas de alface, onde o tratamento na proporção 1:1 de areia e esterco bovino, apresentou as menores médias comparada ao substrato comercial.

O conteúdo de água retido no substrato está diretamente relacionado com o a proporção e dimensão dos poros. Os macroporos são responsáveis pela aeração e drenagem da água, já os microporos tem a capacidade de reter a água por ação da capilaridade (SCHMITZ et al., 2002; SCHREIBER et al., 2018).

Pelos resultados observados, a adição de esterco bovino provocou uma menor aeração, o que pode ser atribuído à diminuição dos macroporos do substrato (OLARIA et al., 2016). Sabe-se que a matéria orgânica causa alterações nas propriedades físicas e químicas do solo e promove uma melhor retenção de umidade pelo aumento do numero de microporos, no entanto, se adicionado em proporções inadequadas, poderá prejudicar a aeração das raízes (OLARIA et al., 2016).

A aeração é essencial para a respiração das células radiculares e, portanto, para o desempenho das plantas em geral (TAlZ et al., 2017). A baixa aeração ocasionada pelo aumento da proporção de esterco no substrato pode estar relacionada às menores médias observadas para o T6. Sob condições de déficit de aeração, as raízes favorecem a respiração anaeróbica devido à redução dos níveis de oxigênio e à geração de ATP. Isso promove uma redução na produção de energia e consequentemente, no crescimento das plantas (TAN et al., 2018).

O maior volume de raízes (VR) observado no tratamento com substrato comercial (T7) em detrimento aos de adição de esterco, mesmo em maiores proporções, $40 \%$ e $50 \%$, se deve ao equilíbrio de características desejáveis de um substrato. O substrato ideal deve proporcionar ao sistema radicular condições 
adequadas de aeração, água, nutrientes, $\mathrm{pH}$, estrutura e sanidade para o seu pleno desenvolvimento (SHAEFER et al., 2015). Para conseguir essas características, os substratos são constituídos por diferentes proporções de materiais, como casca de árvores trituradas, casca de arroz carbonizada, compostos orgânicos, fibra de coco, vermiculita, turfa, musgo, areia entre outros (SHAEFER et al., 2015).

Nas menores proporções de esterco (T1, T2, T3, T4 e T5) não houve diferença estatística entre os tratamentos, o que indica que proporções acima de $40 \%$ são prejudiciais para o desenvolvimento radicular e consequentemente para a muda em geral. Resultado contrário foi observado em tomate (Solanum lycopersicum L.) e berinjela (Solanum melongena L.), onde o substrato na proporção de $50 \%$ de solo e $50 \%$ de esterco bovino proporcionou mudas similares as produzidas com substrato comercial (SANTOS et al., 2021.).

Desse modo, para o morangueiro, as maiores proporções de esterco refletiram negativamente no volume de raízes devido ao aumento da capacidade de retenção de água, o que comprometeu o crescimento radicular.

\section{CONCLUSÕES}

Com os resultados observados nas condições microclimáticas de alto Rio Plantoja, em Santa Maria de Jetibá-ES, se recomenda a utilização do substrato comercial para a produção de mudas de morango da cv. Albion. A adição de esterco bovino no preparo do substrato não influenciou positivamente as características biométricas da muda.

\section{REFERÊNCIAS}

ANTUNES, L.E.C.; REISSER JUNIOR, C. Recomendação da utilização do sistema de produção fora de solo para morangueiro. Embrapa Clima Temperado-Circular Técnica (INFOTECA-E), 2019. Disponível em: https://www.embrapa.br/busca-depublicacoes/-/publicacao/1116421/recomendacao-da-utilizacao-do-sistema-deproducao-fora-de-solo-para-morangueiro.

CEASA, Central de Abastecimento do Espírito Santo. Filtro oferta de produto. Série histórica dos últimos cinco anos. 2020. Disponível em:< http://www.ceasa.es.gov.br>. Acesso em 02 de maio de 2021.

COCCO, C.; GONÇALVES, M. A.; VIGNOLO, G. K.; PICOLOTTO, L.; ANTUNES, L. E. C. Produção de mudas. In: ANTUNES, L.E.C.; REISSER JUNIOR, C.; SCHWENGBER, J. E. (Ed.). Morangueiro. Pelotas: Embrapa Clima Temperado, 2016. p. 79-110. Disponível em: <http://www.infoteca.cnptia.embrapa.br/infoteca/handle/doc/1092843>. Acesso em 25 de maio de 2021.

CRUZ, C. D. GENES - software package for analysis in experimental statistics and quantitative genetics. Acta Scientiarum Agronomy, v. 35, n. 3, p. 271-276, 2013. DOI: https://doi.org/10.4025/actasciagron.v35i3.21251.

DICKSON, A.; LEAF A.L.; HOSNER, J. F. 1960. Quality appraisal of while spruce and white pine seedling stock in nurseries. Forestry Chronicle, v.36, n.1, p.11-13. URL: https://doi.org/10.5558/tfc36010-1.

GRUGIKI, M.A.; LAURETT, L.; ROCON, J.R.; GONÇALVES, M.P.M. Diagnóstico da implantação de sistemas agroflorestais na comunidade Alto Rio Plantoja, no 
município de Santa Maria de Jetibá - ES. In: VIII Simpósio brasileiro de pósgraduação em ciências florestais. Recife - Pe, 2014.p. 424- 427.

INCAPER - Instituto Capixaba de Pesquisa, Assistência Técnica e Extensão Rural. 2021. Programa de Assistência Técnica e Extensão Rural (Proater) 2020-2023. Santa Maria de Jetibá. URL:https://incaper.es.gov.br/proater.

RANGEL JUNIOR, I.M.; OLIVEIRA, A.J.M.; CAVALCANTI, V.P.; RODRIGUES, F.A.; FERREIRA, A.L.P.; PIO, L. A.S. Produção de mudas orgânicas de morangueiro (Fragaria $x$ ananassa Duch.) cultivar Pir cinque em diferentes substratos. Cadernos de Agroecologia, v. 15, n. 2, 2020.

MOURA, R. S.; ALVES, A.U.; RIBEIRO, A.A.; SOARES, J.M.; ANJOS NETO, J.G. Emergência e crescimento inicial de mudas de cultivares de alface em diferentes substratos. Revista Verde. V. 9., n. 4, p. 255-261, out-dez, 2014. URL: http://www.gvaa.com.br/revista/index.php/RVADS.

NINK, E. Reimagining solidarity with strawberry farmworkers in the United States. Journal of Agriculture, Food Systems, and Community Development, v. 10, n. 3, p.1-3. 2021.URL: https://www.foodsystemsjournal.org/index.php/fsj/article/view/968.

OLARIA, M.; NEBOT, J.F.; MOLINA, H.; TRONCHO, P.; BARRACHINA, L.L.; VILARROCHA, E.L. Effect of different substrates for organic agriculture in seedling development of traditional species of Solanaceae. Spanish Journal of Agricultural research, v. 14, n. 1, p. 14, 2016. DOI:10.5424/sjar/2016141-8013.

PMSMJ. Prefeitura Municipal de Santa Maria de Jetibá. Produtor (a) rural santamariense agora conta com Ponto de Apoio na CEASA-ES. 2017. Disponível em < http://www.pmsmj.es.gov.br/portal/produtora-ruralsantamariense-agora-contacom-ponto-de-apoio-na-ceasa-es/> Acesso em: 18 de março de 2019.

ROKA, F.; GUAN, Z. Farm labor management trends in Florida, USA challenges and opportunities. International Journal of Agricultural Management, v. 7, n. 1, p. 1-9, 2018. DOI: 10.5836/ijam/2018-07-79.

SCHAFER, G.; SOUZA, PVD.; FIOR, CSI. Um panorama das propriedades físicas e químicas de substratos utilizados em horticultura no sul do Brasil. Ornamental Horticulture, v. 21, n. 3, p. 299-306, 2015. DOI: 10.14295/oh.v21i3.735.

SCHMITZ, J.A.K.; SOUZA, P.V.D.; KÄMPF, A. N. Propriedades químicas e físicas de substratos de origem mineral e orgânica para o cultivo de mudas em recipientes. Ciência Rural, v. 32, p. 937-944, 2002. URL:https://doi.org/10.1590/S010384782002000600005.

SCHREIBER, C.; SCHIEDUNG, H.; HARRISON, L.; BRIESE, C.; ACKERMANN, B et al. Evaluating potential of green alga Chlorella vulgaris to accumulate phosphorus and to fertilize nutrient-poor soil substrates for crop plants. Journal of Applied Phycology, v. 30, n. 5, p. 2827-2836, 2018. URL: https://doi.org/10.1007/s10811018-1390-9.

SANTOS, A.M.M.; SILVA, M. A.O.; DE SÁ, D. A.; NEVES, L. P. F., GOUVEIA, F.F.N.; COSTA, K. D.S.; Substratos alternativos para a produção de mudas de 
tomate e berinjela. Revista Verde de Agroecologia e Desenvolvimento Sustentável, v. 16, n. 2, p. 206-212, 2021.

TAIZ, L.; ZEIGER, E.; MOLLER, I. M.; MURPHY, A. Fisiologia vegetal e desenvolvimento vegetal. 6를. Porto Alegre: Editora Artmed, 2017.

TAN, X.; XU, H.; KHAN, S.; EQUIZA, M.A.; LEE, S.H.; VAZIRIYEGANEH, M.; ZWIAZEK, J.J. Plant water transport and aquaporins in oxygen-deprived environments. Journal of Plant Physiology, v. 227, p. 20-30, 2018. URL: https://doi.org/10.1016/j.jplph.2018.05.003.

WATERS, E.M.; WATSON, M.A. Live substrate positively affects root growth and stolon direction in the woodland strawberry, Fragaria vesca. Frontiers in Plant Science, v. 6, p. 1-10, 2015. URL: https://doi.org/10.3389/fpls.2015.00814.

WURZ, D. A.; DUBIELA, R. C.; NUNES, H. F.. Perfil socioeconômico de produtores de morango no município de Canoinhas-Santa Catarina. Revista Científica Rural, v. 21, n. 3, p. 13-27, 2019. URL: https://doi.org/10.30945/rcr-v21i3.2721.

ZEIST, A. R.; DE RESENDE, J. T.; LIMA, R. B.; GABRIEL, A.; HENSCHEL, J. M; DA SILVA, I. F. Phenology and agronomic components of first and second-cycle strawberry. Horticultura Brasileira, v. 37, n. 1, p. 29-34, 2019. URL: https://doi.org/10.1590/S0102-053620190104. 